prognostic factor in macular hole surgery. British Journal of Ophthalmology. 2002;86(4):390-393.

8. Colenbrander A. Aspects of vision loss-visual functions and functional vision. Visual impairment research. 2003;5(3):115-136.

9. Ghoraba HH, Leila M, Ghoraba H, Heikal MA, Elgemai EEM. Comparative study between pars plana vitrectomy with internal limiting membrane peel and pars plana vitrectomy with internal limiting membrane flap technique for management of traumatic full thickness macular holes. Journal of ophthalmology. 2019;2019

10. Shao $Q$, Xia $H$, Heussen FM, Ouyang $Y$, Sun $\mathbf{X}$, Fan $\mathbf{Y}$. Postoperative anatomical and functional outcomes of different stages of high myopia macular hole. BMC ophthalmology. 2015;15(1):1-8.

\title{
MộT SỐ YẾU TỐ LIÊN QUAN ĐẾN RỐI LOAN TRÂM CẢM Ở NGƯỜI BÊNNH ĐỘNG KINH TOÀN THỂ
}

\author{
Đỗ Quang Vinh*, Nguyễn Văn Tuấn*
}

\section{TÓM TẮT}

Đắt vấn đê: Rối loạn trâm cảm là bệnh lý hay gặp ở người bênh động kinh toàn thể gây ảnh hưởng lớn đến chất lượng cuộc sống người bệnh, vì vậy việc phát hiện sớm vổ cùng quan trọng. Nhiều yếu tố được cho rằng làm tăng tỷ lế rối loạn trầm cảm ở người bệnh động kinh toàn thể như tuổi người bệnh, tình trạng hổn nhân, tần suất cơn co giật. Có nhiều nghiên cứu trên thế giới về vấn đề này tuy nhiên ở Việt Nam chưa có nghiên cứu nào. Do đó chúng tôi thực hiênn nghiên cứu "một số yếu tố liên quan đển rối loạn trẩm cảm ở người bềnh động kinh toàn thể". Muc tiêu: Tìm hiểu một số yếu tố liên quan đến rối loạn trầm cảm ở người bềnh động kinh toàn thể. Đối tượng và phương pháp nghiên cứu: Nghiên cứu mô tả cắt ngang trên 53 người bệnh có rối loạn trầm cảm trong 243 người bệnh được chẩn đoán động kinh toàn thể, điêu trị ngoại trú tại Bệnh viện Tâm Thần Hà Nội và Trung tâm Y tế Huyện Đông Anh từ tháng 9/2020 đến tháng 07/2021, có sử dụng thang điểm đánh giá trầm cảm Hamilton-D (Ham-D). Kết quả: Trong 243 người bệnh động kinh toàn thể có 53 người bệnh mắc rối loạn trầm cảm chiếm $21,81 \%$. Một số yểu làm tăng nguy cơ mắc rối loạn trâm cảm trong nghiên cứu: tuổi $>40$ $(\mathrm{OR}=2,875, \mathrm{p}<0,001)$, tình trạng hôn nhân độc thân $(\mathrm{OR}=2,039, \mathrm{p}=0,046)$, tuổi khởi phát bệnh ( $\mathrm{OR}=$ $2,763, p=0,009)$, tân suất cơn $>1$ cơn/tháng ( $O R=9,612$, $\mathrm{p}<0,001)$, Đa trị liêu $(\mathrm{OR}=4,097, \mathrm{p}<0,001)$.

Tư khóa: rối lioạn trầm cảm, động kinh toàn thể.

\section{SUMMARY}

SEVERAL ASSOCIATED FACTORS TO

DEPRESSIVE DISORDER IN PATIENTS WITH GENERALIZED EPILEPSY

Background: Depressive disorder is a common disease in generalized epilepsy patients, which greatly affects the patient's quality of life, so early detection is extremely important. Many factors are thought to increase the prevalence of depressive disorder in

*Đại hoc Y Hà Nọi

Chịu trách nhiệm chính: Đỗ Quang Vinh

Email: Quangvinh2321993@gmail.com

Ngày nhận bài: 12.7.2021

Ngày phản biên khoa hoc: 7.9.2021

Ngày duyệt bài: 14.9 .2021 patients with generalized epilepsy, such as the patient's age, marital status, and seizure frequency. Objectives: evaluate some associated factors with depressive disorder in patients with generalized epilepsy. Method: A cross-sectional study on 53 patients with depressive disorder in 243 outpatients diagnosed with generalized epilepsy, treated at Hanoi Mental Hospital and Medical Center of Dong Anh town, from September 2020 to July 2021, using the Hamilton-D depression rating scale (Ham-D).. Results: Among 243 generalized epilepsy patients, 53 patients had depressive disorder (21,81\%). Some associated factors increase the risk of depressive disorder in the study: age $>40(\mathrm{OR}=2.875, \mathrm{p}<0.001)$, single marital status $(\mathrm{OR}=2.039, \mathrm{p}=0.046)$, age of onset $(\mathrm{OR}=2.763, \mathrm{p}=0.009)$, frequency of seizure $>1$ seizure/month $(\mathrm{OR}=9.612, \quad \mathrm{p}<0.001)$, poly-therapy (OR=4,097, $\mathrm{p}<0.001)$.

Keywords: associated factors, depressive disorder, generalized epilepsy.

\section{I. ĐĂT VẤN ĐỀ}

Động kinh là một bệnh lý thân kinh mạn tính phổ biến do nhiều nguyên nhân gây ra với đặc trưng là sự rối loạn thân kinh trung ương theo từng cơn do sự phóng điện đột ngột, quá mức của các tế bào thân kinh gây ra các triệu chứng trên lâm sàng. Tỉ lệ người bị động kinh trên thế giới chiếm 0,3 - 1\% dân số [1] con số này tương tự tại Việt Nam. Trong đó, người bệnh động kinh toàn thể chiếm tỷ lệ cao nhất.

Trong các rối loạn tâm thân ở người bệnh động kinh toàn thể, rối loạn trâm cảm gây ảnh hưởng lớn đến chất lượng sống của người bệnh[2]. Theo Mazza (2006) nghiên cứu đã chỉ ra rằng khoảng $8 \%$ nguyên nhân chết ở người bệnh động kinh có liên quan đến tự sát và có các triệu chứng của rối loạn trầm cảm[3]. Một số yếu tố của động kinh toàn thể có thể ảnh hưởng tới rối loạn trầm cảm ở người bệnh được báo cáo như: tuổi khởi phát bệnh, tân suất cơn co giật, phương pháp điều trị, thời gian bị bệnh.

Ở nước ngoài đã có nhiêuu nghiên cứu vê các 
yếu tố liên quan tới rối loan trầm cảm ở người bệnh động kinh. Tuy nhiền nghiên cứu về rối loạn trầm cảm ở người bệnh dộng kinh toàn thể chưa nhiều, chủ yếu là các bài báo lẻ tẻ. Các nghiên cứu ở Việt Nam chưa có nghiên cứu sâu nào về các yếu tố liên quan tới rối loạn trầm cảm ở người bệnh động kinh toàn thể. vì vậy chúng tôi tiến hành nghiên cứu này với mục tiêu: "một số yếu tố liên quan đến rối loạn trầm cảm ở người bệnh động kinh toàn thể".

\section{II. ĐỐI TƯợNG VÀ PHƯƠNG PHÁP NGHIÊN CỨU \\ 2.1 Đối tượng nghiên cứu:}

Tiêu chuẩn lựa chon. Tất cả người bênh được chẩn đoán động kinh toàn thể theo ICD-10 (1992) và đáp ứng, tiêu chuẩn loại trừ từ tháng 9/2020 đến tháng 5/2021 tại Bệnh viện Tâm thần Hà Nội và Trung Tâm y tế Huyện Đông Anh.

Tiêu chuẩn loại trừ:

- Người bệnh có rối loạn ý thức ngoài cơn động kinh hoặc khó tiếp xúc trong quá trình thu thập thông tin.

- Người bệnh lạm dụng rượu, bia, ma túy.

- Người bệnh có cơn động kinh do các bệnh lý thực tổn cấp tính.

- Người bệnh có trầm cảm từ trước khi bị động kinh.

- Người bệnh không đồng ý nghiên cứu

\subsection{Phương pháp nghiên cứu:}

- Thiết kế nghiên cứu của chúng tôi dựa trên nghiên cứu cắt ngang với cách chọn mẫu thuận tiện. Từ mục tiêu nghiên cứu xây dựng bệnh án nghiên cứu phù hợp, tiến hành phỏng vấn và khám tâm thần bệnh nhân, sử dụng thang điểm Ham-D để đánh giá mức độ trầm cảm

- Nhập và xử lý số liệu bằng phần mềm SPSS
22. Tiến hành phân tích thống kê mô tả, tính tần suất của các biểu hiện, so sánh các tỉ lệ, tính tương quan.

2.3 Đạo đức nghiên cứu: Đây là một nghiên cứu mô tả lâm sàng, nhằm phát hiện kịp thời rối loạn trầm cảm ở người bệnh động kinh toàn thể. Đối với những trường hợp có rối loạn trầm cảm, người bệnh được tư vấn thêm về bệnh. Người bệnh được giải thích mục đích của nghiên cứu trước khi tham gia, các thông tin do người bệnh cung cấp được đảm bảo giữ bí mật. Người bệnh không phải chi trả bất cứ chi phí khám bệnh, trắc nghiệm tâm lý. Nghiên cứu đã được sự đồng ý của trường Đại học Y Hà Nội và cơ sở nghiên cứu.

\section{KẾT QUẢ NGHIÊN CỨU}

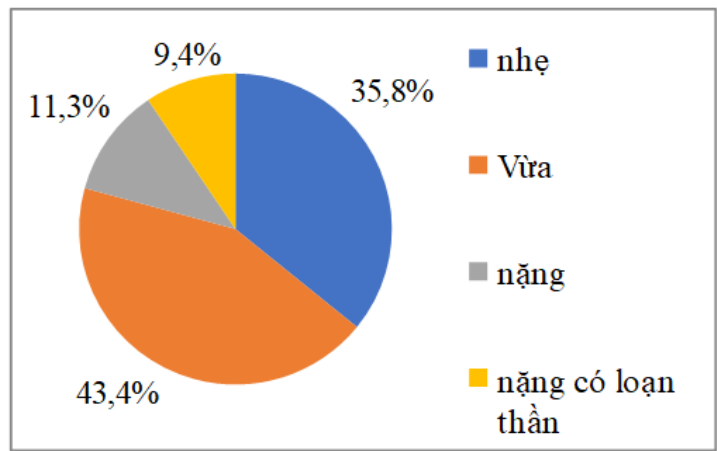

Biểu đồ 1: Mức độ rối loạn trầm cảm nhóm người bệnh nghiên cứu theo ICD-10(N=53)

Nhận xét: Nhóm người bệnh rối loạn trầm cảm mức độ vừa chiếm tỷ lệ lớn nhất là $43,4 \%$, tiếp đến là nhóm mức độ nhẹ với tỷ lệ là 35,8\%. Nhóm nặng và nặng có loạn thần lần lượt chiếm tỷ lệ $11,3 \%$ và $9,4 \%$.

Bảng 1: Môi liên quan giữa các yếu tố nhân khẩu học với rôii loạn trâm cảm

\begin{tabular}{|c|c|c|c|c|c|c|c|}
\hline \multirow{2}{*}{\multicolumn{2}{|c|}{ Yếu tố }} & \multicolumn{2}{|c|}{ Không trầm cảm } & \multicolumn{2}{|c|}{ Có trầm cảm } & \multirow{2}{*}{ OR } & \multirow[b]{2}{*}{$\mathbf{p}$} \\
\hline & & $\mathbf{n}$ & $\%$ & $\mathbf{n}$ & $\%$ & & \\
\hline \multirow{2}{*}{ Giới } & Nam & 116 & 81,1 & 27 & 18,9 & \multirow[b]{2}{*}{1,51} & \multirow[b]{2}{*}{0,186} \\
\hline & Nữ & 74 & 74 & 26 & 26 & & \\
\hline \multirow{2}{*}{ Tuổi } & $<40$ & 101 & 87,1 & 15 & 12,9 & \multirow{2}{*}{2.875} & \multirow{2}{*}{0,001} \\
\hline & $\geq 40$ & 89 & 70,1 & 38 & 29,9 & & \\
\hline \multirow{2}{*}{$\begin{array}{l}\text { Hôn } \\
\text { nhân }\end{array}$} & Độc thân & 71 & 85,5 & 12 & 14,5 & \multirow{2}{*}{2.039} & \multirow{2}{*}{0,046} \\
\hline & Đã kết hôn & 119 & 74,4 & 41 & 25,6 & & \\
\hline \multirow{2}{*}{ Nơi ở } & Thành phố & 57 & 77,0 & 17 & 23,0 & \multirow{2}{*}{0,908} & \multirow[t]{2}{*}{0,772} \\
\hline & Nông thôn, vùng núi & 133 & 78,7 & 36 & 21,3 & & \\
\hline \multirow{2}{*}{ Học vấn } & $<$ THPT & 151 & 80,3 & 37 & 19,7 & \multirow{2}{*}{1,674} & \multirow{2}{*}{0,137} \\
\hline & $\geq$ THPT & 39 & 70,9 & 16 & 29,1 & & \\
\hline
\end{tabular}

Nhận xét: Nữ giới có tỷ lệ mấc trầm cảm cao hơn nam giới tuy nhiên sự khác biệt không có ý nghĩa thống kê $(p>0,05)$. Tuổi $\geq 40$ có nguy cơ mắc trầm cảm cao so với người < 40 tuổi $(O R=2,875$, $\mathrm{p}=0,001$ ). Đã kết hôn có nguy cơ mấc trầm cảm cao gấp 2,039 lần so với người đang độc thân và có ý nghĩa thống kê $(p=0,046)$. Người bệnh tốt nghiệp THPT trở lên có tỷ lệ mắc trầm cảm cao hơn so với nhóm chưa tốt nghiệp THPT, tuy nhiên sự khác biệt không có ý nghĩa thống kê. 
Bảng 2. Môi liên quan giữa một số yêu tố bệnh động kinh tới rôi loạn trầm cảm

\begin{tabular}{|c|c|c|c|c|c|c|c|}
\hline \multirow{2}{*}{\multicolumn{2}{|c|}{ Yếu tố $\quad$ Mức độ }} & \multicolumn{2}{|c|}{ Không trâm cảm } & \multicolumn{2}{|c|}{ Có trầm cảm } & \multirow{2}{*}{ OR } & \multirow[b]{2}{*}{$\mathbf{p}$} \\
\hline & & $\mathrm{n}$ & $\%$ & $\mathrm{n}$ & $\%$ & & \\
\hline \multirow{2}{*}{$\begin{array}{c}\text { Tuối khởi } \\
\text { phát }\end{array}$} & $<40$ & 170 & 81,0 & 40 & 19,0 & \multirow{2}{*}{2,763} & \multirow{2}{*}{0,009} \\
\hline & $\geq 40$ & 20 & 60,6 & 13 & 39,4 & & \\
\hline \multirow{2}{*}{$\begin{array}{c}\text { Số năm bị } \\
\text { bệnh }\end{array}$} & $<10$ & 49 & 73,1 & 18 & 26,9 & \multirow{2}{*}{0,676} & \multirow{2}{*}{0,239} \\
\hline & $\geq 10$ & 141 & 80,1 & 35 & 19,9 & & \\
\hline \multirow{2}{*}{$\begin{array}{c}\text { Tân suất } \\
\text { cơnn }\end{array}$} & $<1$ cơn/tháng & 164 & 88,6 & 21 & 11,4 & \multirow{2}{*}{9,612} & \multirow{2}{*}{$<0,001$} \\
\hline & $\geq 1$ cơn/tháng & 26 & 44,8 & 32 & 55,2 & & \\
\hline \multirow{2}{*}{ Điều trị } & Đơn trị liệu & 156 & 84,8 & 28 & 15,2 & \multirow{2}{*}{4,097} & \multirow{2}{*}{$<0,001$} \\
\hline & Đa trị liệu & 34 & 57,6 & 25 & 42,4 & & \\
\hline
\end{tabular}

Nhận xét: Các yếu tố làm tăng nguy cơ mắc rối loạn trầm cảm là tuối khởi phát> $40(\mathrm{OR}=2,763$, $\mathrm{p}=0,009)$, tần suất $>1 \mathrm{cơn} /$ tháng $(\mathrm{OR}=9,612, \mathrm{p}<0,001)$, đa trị liệu $(\mathrm{OR}=4,097, \mathrm{p}<0,001)$.

\begin{tabular}{|c|c|c|c|c|c|c|c|}
\hline \multirow{2}{*}{\multicolumn{2}{|c|}{$\begin{array}{l}\text { Mức độ trâm cảm } \\
\text { Yếu tố }\end{array}$}} & \multicolumn{2}{|c|}{ Nhẹ và vừa } & \multicolumn{2}{|c|}{ Năng } & \multirow{2}{*}{ OR } & \multirow[b]{2}{*}{$\mathbf{p}$} \\
\hline & & $\mathbf{n}$ & $\%$ & $\mathbf{n}$ & $\%$ & & \\
\hline \multirow[b]{2}{*}{ Giới } & Nam & 20 & 74,1 & 7 & 25,9 & \multirow{2}{*}{$\begin{array}{c}0,519 \\
(0.132-2.044)\end{array}$} & \multirow[b]{2}{*}{$>0,05$} \\
\hline & Nữ & 22 & 84,6 & 4 & 15,4 & & \\
\hline \multirow{2}{*}{ Tuô̂i } & $<40$ & 12 & 80,0 & 3 & 20,3 & \multirow{2}{*}{$\begin{array}{c}1,067 \\
(0.241-4.715)\end{array}$} & \multirow{2}{*}{$>0,05$} \\
\hline & $\geq 40$ & 30 & 78,9 & 8 & 21,1 & & \\
\hline \multirow{2}{*}{$\begin{array}{l}\text { Hôn } \\
\text { nhân }\end{array}$} & Độc thân & 10 & 83,3 & 2 & 16,7 & \multirow{2}{*}{$\begin{array}{c}1,406 \\
(0,26-7,611)\end{array}$} & \multirow{2}{*}{$>0,05$} \\
\hline & Có gia đình & 32 & 78,0 & 9 & 22,0 & & \\
\hline \multirow[b]{2}{*}{ Nơi ở } & Thành phố & 13 & 76,5 & 4 & 23,5 & \multirow{2}{*}{$\begin{array}{c}0,784 \\
(0,195-3,155) \\
\end{array}$} & \multirow{2}{*}{$>0,05$} \\
\hline & Nông thôn & 29 & 80,6 & 7 & 19,4 & & \\
\hline \multirow{2}{*}{$\begin{array}{l}\text { Tuổi khởi } \\
\text { phát }\end{array}$} & $<40$ & 31 & 77,5 & 9 & 22,5 & \multirow{2}{*}{$\begin{array}{c}0,626 \\
(0,117-3,359)\end{array}$} & \multirow{2}{*}{$>0.05$} \\
\hline & $\geq 40$ & 11 & 84,6 & 2 & 15,4 & & \\
\hline \multirow{2}{*}{$\begin{array}{l}\text { Số năm } \\
\text { bị bệnh }\end{array}$} & $<10$ & 13 & 72,2 & 5 & 27,8 & \multirow{2}{*}{$\begin{array}{c}0,538 \\
(0,139-2,086) \\
\end{array}$} & \multirow{2}{*}{$>0.05$} \\
\hline & $\geq 10$ & 29 & 82,9 & 6 & 17,1 & & \\
\hline \multirow{2}{*}{$\begin{array}{l}\text { Tần suất } \\
\text { cơn }\end{array}$} & $<1$ cơn /tháng & 18 & $\begin{array}{l}85,7 \\
750\end{array}$ & 3 & 14,3 & \multirow{2}{*}{$\begin{array}{c}2,00 \\
(0,464-8,619)\end{array}$} & \multirow{2}{*}{$>0,05$} \\
\hline & $\geq 1$ cơn /tháng & 24 & 75,0 & 8 & 25,0 & & \\
\hline \multirow{2}{*}{ Điều trị } & Đơn trị liệu & 22 & 78,6 & 6 & 21,4 & \multirow{2}{*}{$\begin{array}{c}0,917 \\
(0,242-3,474) \\
\end{array}$} & \multirow{2}{*}{$>0,05$} \\
\hline & Đa trị liệu & 20 & 80,0 & 5 & 20,0 & & \\
\hline
\end{tabular}

Nhận xét: Không có yếu tố nào làm tăng mức độ của rối loạn trầm cảm có ý nghĩa thống kê.

\section{BÀN LUÂ̂N}

Chúng tôi đã thực hiện khảo sát về các yếu tố nhân khẩu học gồm tuổi, giới, nghề nghiệp và hoàn cảnh sống của nhóm đối tượng nghiên cứu. Tỷ lệ mắc rối loạn trầm cảm ở người bệnh động kinh toàn thể là $19,8 \%$, phù hợp với các nghiên cứu khác trên thế giới[4].

Bảng 1 cho thấy mối liên quan một số yếu tố nhân khẩu học với rối loạn trầm cảm ở người bệnh động kinh toàn thể. Kết quả cho thây các yếu tố làm tăng nguy cơ mắc rối loạn trầm cảm có ý nghĩa thống kê bao gồm: Tuổi $\geq 40$ (OR= $2,875, p=0,001)$ và đã kết hôn $(O R=2,039$, $\mathrm{p}=0,046)$. Các yếu tố: Nữ giới và tốt nghiệp THPT có tỷ lệ mắc rối loạn trầm cảm cao hơn tuy nhiên sự khác biệt không có ý nghĩa thống kê $(p>0,05)$, kết quả này phù hợp với các nghiên cứu khác. $[5,6]$.

Bảng 2 cho thãy mối liên quan một số yếu tố của bệnh với rối loạn trầm cảm ở người bệnh động kinh toàn thể. Các yếu tố làm tăng nguy cơ mắc rối loạn trầm cảm có ý nghĩa thống kê là: tuổi khởi phát> $40(\mathrm{OR}=2,763, \mathrm{p}=0,009)$, tần suất $>1$ cơn/tháng $(O R=9,612, p<0,001)$, đa trị liệu $(O R=4,097, p<0,001)$. Điều này phù hợp với các nghiên cứu khác[7, 8].

Bảng 3 thể hiện mối liên quan một số yếu tố tới mức độ rối loạn trầm cảm. nghiên cứu của chúng tôi cho thây không có sự khác biệt có ý nghĩa thống kê giữa các yếu tố với mức độ rối loạn trầm cảm. Điều này cũng phù hợp với các nghiên cứu khác.

\section{KẾT LUẬN}

Rối loạn trầm cảm thường gặp ở người bệnh động kinh toàn thể $(21,81 \%)$. Các yếu tố liên quan tới việc mắc rối loạn trầm ở người bệnh động kinh toàn thể trong nghiên cứu của chúng tôi bao gồm: Tuổi của người bệnh $>40$ tuổi $(\mathrm{OR}=2,875, \mathrm{p}<0,001)$, tình trạng hôn nhân độc thân (OR:2,039, $p=0,046)$, tuổi khởi phát bệnh 
$(\mathrm{OR}=2,763, \mathrm{p}=0,009)$, tân suất cơn $>1$ cơn/tháng $(O R=9,612, p<0,001)$, đa trị liệu $(\mathrm{OR}=4,097, p<0,001)$. Các yếu tố khác như nơi ở, trình độ học vấn, số năm bị bệnh động kinh không ảnh hưởng tới việc mắc rối loạn trầm cảm. Không có yếu tố nào làm tăng mức độ rối loạn trầm cảm có ý nghĩa thống kê

\section{TÀI LIÊU THAM KHẢO}

1. Neligan, A., W.A. Hauser, and J.W. Sander, The epidemiology of the epilepsies. Handb Clin Neurol, 2012. 107: p. 113-33.

2. Miller, J.M., et al., Depressive Symptoms in Epilepsy Prevalence, Impact, Aetiology, Biological Correlates and Effect of Treatment with Antiepileptic Drugs. 2008.
3. Mazza, M., P. Bria, and S. Mazza, Depression and suicide in epilepsy: fact or artefact? J Neurol Sci, 2007. 260(1-2): p. 300-1.

4. Gupta, S., et al., Depression and anxiety in patients with epilepsy. International Journal of Advances in Medicine, 2018. 5(5): p. 1268.

5. Berhanu Boru Bifftu, B.A.D., Bewket Tadesse Tiruneh and Nigusie Birhan Tebeje, Depression among people with epilepsy in Northwest Ethiopia: a cross-sectional institution based study. 2015.

6. Triantafyllou, N.I., et al., Patterns of depressive symptoms in epilepsy. 2012.

7. Kumar, $\mathbf{N}_{\text {., }}$ et al., Depressive Symptom Severity in Individuals With Epilepsy and Recent Health Complications. J Nerv Ment Dis, 2019. 207(4): p. 284-290.

8. Nair, P.P.C., S. C. Menon, V. Wadwekar, V., High Frequency of Depressive Symptoms among Adults with Epilepsy: Results from a Hospital-based Study. J Neurosa Rural Pract, 2017. 8(Suppl 1): p. S13-S19.

\title{
CHẨN ĐOÁN HIỄU ỨNG ÁO CHOÀNG TRẮNG BẰNG HOLTER HUYẾT ÁP 30 PHÚT
}

\author{
Châu Hưu Hầu*, Hia Kim Khuê*, Quách Lâm Thanh Trúc*
}

\section{TÓM TẮT}

Nghiên cứu có mục tiêu xác định và loại trừ hiêuu ứng tăng huyết áp áo choàng trắng bằng đo huyết ảp lưu động 30 phút tại tuyến y tế cơ sở. Đối tượng nghiên cứu: Bệnh nhân đến khám tại các buồng khám thuộc Khoa Khám bệnh của bệnh viện Nhật Tân thành phố Châu Đốc, trong 8 tháng từ 1/10/2020 cho đến $31 / 5 / 2021$, có tăng huyết áp mà bác sĩ khám nghĩ đến hiệu ứng áo choàng trắng. Số bản ghi kết quả đo huyết áp lưu động ít nhất 8 lần trong 30 phút là 163. Phương pháp nghiên cứu: Thuần tập với Holter $\mathrm{HA}$ hiệu Norav, NBP-24 NG; có phân tích so sánh kết quả về tân số tăng huyết áp giữa các phương pháp đo. Kết quả: Tổng số có 163 người được ghi huyết áp lưu động 30 phút đây đủ, trong đó nữ 93 , chiếm $57 \%$; tuổi từ 14 đến 86, trung bình là 48,7 $\pm 14,5$. Kết quá đo huyết áp tại buồng khám cho thấy: Bác sĩ chẩn đoán có 107 người mắc tăng huyết áp $(65,6 \%)$. Tuy nhiên sau khi có kết quả đo huyết áp lưu động 30 phút, số bệnh nhân thực sự cần điều trị tăng huyết áp chi còn 74 người $(45,4 \%)$, giảm 33 người $(20,2 \%)$. Kết luận: Nghiên cứu cho thấy phương pháp đo huyết áp lưu động 30 phút giúp phát hiện và giảm hiệu ứng tăng huyết áp áo choàng trắng khoảng $20,2 \%$ trong số được chẩn đoán tăng huyết áp tại buồng khám, qua đó giúp chẩn đoán người bệnh tăng huyết áp thực sự sau khi loại trừ tăng huyết áp áo choàng trắng, góp phân giảm chi phí, tác dụng phụ và

*Bệnh viện Nhật Tân

Chịu trách nhiệm chính: Châu Hữu Hầu

Email: benhviennhattan@gmail.com

Ngày nhận bài: 9.7.2021

Ngày phản biện khoa họ: 7.9.2021

Ngày duyệt bài: 13.9.2021 góp phần tăng hiệu quả chữa trị cho người bệnh tăng huyết áp.

Tư khóa: Tăng huyết áp; hiệu ứng áo choàng trắng; HA lưu động 30 phút; Bệnh viện Nhật Tân.

\section{SUMMARY \\ DIAGNOSIS OF THE WHITE COAT EFFECT BY 30-MINUTE OFFICE BLOOD PRESSURE MONITORING (OBP30)}

Patients who came to the examination rooms of the Out-Patient Examination Department of Nhat Tan hospital with hypertension that the doctor thought about the white coat effect during 8 months from October 1, 2020 to May 31, 2021. The number of patients with OBP30 measured was 163 including records with at least 8 readings. Methods: Cohort. Blood Pressure Monitoring device was Norav, NBP-24 NG. Results: A total of 163 patients were recorded with full OBP30, of which 93 were female, accounting for $57 \%$. Age 14 to 86 . Mean age was $48.7 \pm 14.5$. When measuring OBP and someone showing signs of hypertension, the doctor thought that 107 people should be treated $(65.6 \%)$. After getting the results of OBP30, the doctor only prescribed antihypertensive treatment for 74 people $(45.4 \%)$, reduced 33 people, and the rate of reduction in hypertension treatment was $20.2 \%$. Conclusion: Our study shows that OPB30 reduces the effect of White Coat Effect about $20.2 \%$ of cases with identified office hypertension. Thereby, treating hypertensive patients and monitoring White Coat Effect patients will be more effective as well as reducing costs and side effects for them.

Key words: Hypertension; Office Blood Pressure (OBP), 30-MinuteOBP Monitoring (OBP30), White coat effect; Nhat Tan hospital. 